\title{
versants
}

\section{La censura y Miguel Hernández}

\author{
Aitor L. LARRABIDE \\ Director de la Fundación Cultural Miguel Hernández
}

\begin{abstract}
Este trabajo es un resumen del libro homónimo, escrito con Juan José Sánchez Balaguer y la extraordinaria participación de Nerea Pérez Rubio, mientras redactamos estas líneas (enero 202I), que será publicado a finales de 202I. La documentación procede, en su mayor parte, del Archivo General de la Administración (AGA), además del Archivo Histórico Provincial de Alicante (AHPA) y de la Biblioteca Pública del Estado «Fernando de Loazes» de Orihuela, instituciones a las que deseamos agradecer su colaboración.
\end{abstract}

Keywords: censura, Miguel Hernández, franquismo, historia del siglo xx, poesía del siglo xx.

\section{Censura}

La palabra censura proviene de la latina censor, que era el trabajo de dos romanos cuya función consistía en supervisar el comportamiento del público y la moral; por lo tanto, censuraban la forma de actuar. Existen diferentes tipos de censura: moral, política, religiosa, corporativa... Nosotros, obviamente, no vamos a remontarnos tan alto, sino que trataremos de esbozar muy brevemente el panorama de la censura literaria en un periodo determinado -aunque largo- de la historia de España, como fue el régimen de Franco, para centrarnos finalmente en el objeto de nuestro interés: la censura referida a la figura del poeta oriolano y universal Miguel Hernández, en concreto a las ediciones de su obra poética y teatral, representaciones de sus obras teatrales, obras o recitales inspirados en poemas hernandianos, textos no radiables, grabaciones fonográficas con poemas musicados, algunos actos públicos prohibidos, y un epígrafe breve dedicado a la censura cinematográfica.

Se trata, sin duda, por varios motivos, del proyecto más ambicioso y también más complejo de los realizados por nuestra Entidad: a la dificultad de acceso a la documentación y el necesario acompañamiento del contexto jurídico, por una parte, se añade, por otra, una glosa o comentario a cada edición de la que exista un expediente administrativo para que el/la lector/a pueda valorar, en su justa medida, los libros que sufrieron el obligado trance de la censura.

Somos conscientes de que, por ejemplo, la censura se aplicó con celo en monografías, como las dos pioneras de Juan Guerrero Zamora' , y, en menor

I Noticia sobre Miguel Hernández (I95I) y Miguel Hernández, poeta (I9IO-I942) (I955), que sufrió 
medida, en poemarios o revistas literarias, por considerarlos minoritarios. Quizá en otra ocasión sea posible trabajar en este aspecto de la crítica hernandiana que ahora solo esbozamos de manera tan breve para no alejarnos de nuestro principal objetivo: la obra del poeta.

«Censura literaria», según Abellán, es:

el conjunto de actuaciones del estado, grupos de hecho o de existencia formal capaces de imponer a un manuscrito o a las galeradas de la obra de un escritor -con anterioridad a su difusión- supresiones o modificaciones de cualquier clase, contra la voluntad o beneplácito del autor. El cotejo de la versión original con el texto publicado suele revelar el grado de incidencia de esta clase de actuación censoria (1987: 16).

El confusionismo sobre el hecho censorio se debe, en opinión de Abellán (I5), a la falta de información y el hermetismo en relación con los efectos de la censura. Añade que «la llamada "transición" ha contribuido en gran medida -activa y pasivamente- al desinterés práctico por el estudio de la represión cultural y física durante el franquismo» (15).

El I de febrero de 1964 el hispanista holandés J. Lechner (1975: I42-I46) envió una encuesta a varios poetas sobre la influencia de la censura en el proceso de escritura de sus obras. José Agustín Goytisolo, por ejemplo, contestó que cuando en primera instancia le suprimieron poemas, se desplazaba a Madrid a discutirlo con los responsables. Y según la respuesta de su mujer: «siempre ha podido sacar más de lo que en principio habían permitido». En general, los autores se autocensuran y ya saben de antemano qué pueden tolerar los censores y qué no (Ramón de Garciasol, Ángela Figuera Aymerich, Ángel Crespo y Gabino-Alejandro Carriedo). Garciasol añade que la censura trajo consigo, como hecho positivo, al menos en su caso, «contener el estilo, afinar la metáfora, el concepto y la alusión» (Lechner 1975: I43). Ángela Figuera Aymerich alude a un poema dedicado a Miguel Hernández, traducido al francés, que fue censurado. Dice no recordar dónde fue publicado. Añade que la censura «nos favorece el enseñarnos a decir de modo a la vez claro y velado, a sintetizar mucho sentido en una frase clave» (I43). Para la poeta vasca, la poesía española, desde 1939 hasta la «actualidad» (I964), nace de las circunstancias, y la censura es una de ellas: «Es una poesía, en cierto modo, clandestina y de guerra, la continuación de la guerra, sorda y

un retraso de cuatro años en su publicación y causó un gran revuelo entre los inmovilistas del régimen. El propio Guerrero Zamora publicó un artículo, «Mi libro sobre Miguel Hernández» (1980), en respuesta al libro de memorias de Josefina Manresa publicado en ese mismo año de 1980. Relata el proceso de documentación de su libro y cómo conoció a la viuda de Hernández. Las «amputaciones inevitables» (Guerrero Zamora 1980) de su libro fueron, en su opinión, el tributo a la publicación del libro. Ante el riesgo de un probable secuestro, se envió a América el resto de la edición. 
sangrante» (I43). El poeta de origen burgalés, Victoriano Crémer, afirma que si la censura no hubiera existido:

Es seguro que la poesía que hoy "se practica" no hubiera ni siquiera nacido. Porque lo que determina la especial forma y sentido de nuestra poesía actual es la Censura, aliada con la técnica del "encauzamiento", a base de las publicaciones del Opus o bajo su influencia (Lechner 1975: I44).

De la misma opinión es José Ángel Valente, que afirma lo siguiente: «Creo que la censura y todo el orden de cosas al que la censura responde ha influido decisivamente sobre la poesía española de la posguerra civil» (I44). Ángel González sostiene, por el contrario, que «La censura es una consecuencia. En gran parte, la poesía española es otra consecuencia de la misma causa. La poesía es el género menos afectado por la censura» (I45). Ángel Crespo, a la pregunta de si la censura no hubiera existido, responde que la poesía hubiera tomado otro rumbo o camino, se hubiera escrito Sombra del paraíso (Vicente Aleixandre 1944), «pero tal vez no Hijos de la ira (Dámaso Alonso 1944), que se habrían escrito los versos de García Nieto, pero no los de Miguel Hernández» (I45). Y el poeta palentino Gabino-Alejandro Carriedo responde del siguiente modo a la pregunta de si su poesía -de no haber existido la censura- también hubiera tomado otro camino: «Sí; hubiera dicho más cosas y más bellamente. Me hubiera preocupado sólo de hallar nuevas formas de expresión» (I46).

\section{Abellán, pionero en el estudio de la censura literaria}

Abellán fue el primer investigador en dar a conocer sus pioneros trabajos sobre la censura literaria en el libro Censura y creación literaria en España (I939-I976), publicado en Barcelona por Ediciones Península en I980. Casualidad o no, la misma editorial publicaría un año después la tesis doctoral de Román Gubern: La Censura. Función política y ordenamiento jurídico bajo el franquismo (I936-I975).

Ya un año antes de su libro, Abellán publicó un artículo en el que resumía su trabajo de investigación: «Análisis cuantitativo de la censura bajo el franquismo (1955-1976)», que vio la luz en el número 28 de la revista Sistema. Revista de Ciencias Sociales.

Manuel L. Abellán relata cómo en septiembre de 1976 se comprometió a omitir el nombre de los censores porque fue una condición impuesta:

Durante el lapso de tiempo transcurrido entre mi consulta de documentos en los archivos del MIT y el momento en que se me autorizó la consulta en Alcalá, se efectuó el traslado de varios centenares de cajas correspondien- 
tes a los expedientes de los años 1964, 1965, I966, 1967, I968 y 1969. En Alcalá pude comprobar que los expedientes habían sido despojados de toda documentación antes de ser trasladados, salvo la referente al dictamen y al manuscrito o galeradas de la obra. A último de agosto de 1977 informé al ministro Pío Cabanillas, aporté las pruebas del expurgo y aún es hora de que se averigüe a dónde han ido a parar los documentos de 6I.40I expedientes que acompañaban a las resoluciones dictaminadoras (I980: IO9-IIO).

El mismo investigador, en un texto publicado siete años después, rememora cómo el general Sabino Fernández Campo, que después fue jefe de la Casa del Rey Juan Carlos I, en calidad de subsecretario del Ministerio de Información y Turismo, autorizó por primera vez en 1976 a un investigador consultar los archivos de la censura. A los quince días, las presiones fueron de tal calibre que se le impidió continuar con la consulta (1987:25).

En relación con la protección del anonimato de los censores, Abellán revela que en noviembre de 1976, el entonces Director General de Cultura Popular, Miguel Cruz Hernández, le escribía lo siguiente:

[...] en el caso de la investigación que usted realiza, en los expedientes figura el informe de los lectores, que no son funcionarios, sino personas contratadas para una función específica y confidencial y por lo tanto, carentes de responsabilidad. Los responsables son el Jefe de la Sección, el Subdirector General y en último extremo el Director General... particularmente, creo que es un error haber incluido en el archivo las opiniones de esos lectores, tanto en los casos en que su opinión ha influido positivamente en los responsables, como en aquellos otros en que éstos no lo han hecho suya. Si se identificase al lector que ha dado un informe confidencial y no siendo funcionario, dicho lector tendría pleno derecho a recurrir contra la propia Administración que no ha observado las cautelas oportunas para mantener la pertinente reserva (1987: 2I-22).

Sin embargo, Daniel Gozalbo Gimeno, refuta esta denuncia de Abellán y afirma que nunca se perdieron esos documentos. Además, describe los sabrosos pormenores de las vicisitudes del actual Archivo General de la Administración (en adelante, AGA), desde las transferencias documentales, inundaciones, cambios de locales, etc. (2017:30-3I).

Con posterioridad, el pionero estudioso coordinará en 1987 el monográfico «Fenómeno censorio y represión literaria» del número 5 de la revista holandesa Diálogos Hispánicos de Amsterdam.

A partir de los trabajos de Abellán, se han publicado otros específicos, como los de Lucía Montejo Gurruchaga sobre Blas de Otero (I998: 49I-5I6), (2010: I83-196), y Ángela Figuera (2000: I69-177). En el caso de Rafael Alberti, por ejemplo, citamos la monografía de María Antonia de Isabel-Estrada (2002). El sitio web www.represura.es recoge el proyecto inicial surgido en 
2006 alrededor de la represión y la censura aplicadas al libro, promovido por el Área de Literatura de la Universidad de Alcalá.

Desde 2006 se han sucedido proyectos de investigación, todavía escasos y parciales, relacionados con la censura literaria. En gran medida, en ello tiene mucho que ver la dificultad de acceso a la documentación administrativa depositada en diversos centros oficiales, además de otras consideraciones no menores, como la pérdida efectiva de documentación. Un ejemplo del creciente interés por difundir esa extraordinaria documentación es que el propio Archivo General de la Administración organizó la exposición «Octavio Paz: Guerra, Censura y Libertad», desde febrero a marzo de 20I5, en la que se exhibieron catorce informes de censura de ediciones del escritor y ensayista mexicano.

Más recientemente, la revista Ínsula ha dedicado un interesante número monográfico a la censura literaria bajo el franquismo, coordinado por Araceli Iravedra (2020).

\section{El caso de Miguel Hernández}

A partir de los años cuarenta, tras la Guerra Civil española, la figura de Miguel Hernández estaba prohibida en prensa y radio oficial españolas. El rayo que no cesa, escrito en 1935 y publicado en enero de 1936, no volvió a editarse hasta 1949 por Espasa-Calpe Argentina. La tercera edición no llegó hasta diez años más tarde, ya que, como afirma Juan Cano Ballesta:

aunque el libro circulaba con cierta tolerancia no era fácil el acceso al mismo, no era expuesto en los escaparates de las librerías, ni estaba permitido cualquier tipo de promoción. [...] la censura también hizo ímprobos esfuerzos por ocultar al lector español la faceta política del poeta de Orihuela (2010: I, I39).

El mismo estudioso recordaba hasta qué punto llegaba la persecución contra el poeta oriolano:

A veces era difícil acceder a ellas [revistas] y otras la censura, simplemente, las había mutilado suprimiendo artículos o colaboraciones sobre escritores contrarios al régimen. Así me ocurrió en cierta ocasión buscando un artículo publicado por la Revista de la Universidad de Buenos Aires. Yo traía la ficha completa y exacta sobre el número, año y volumen. El tomo en cuestión estaba, según los ficheros, en la Biblioteca Nacional, pero cuando éste llegó a mis manos comprobé con sorpresa que en él faltaban precisamente todas las páginas del ensayo que yo buscaba (Ángel Rodríguez Segurado, «Dolor y sole-

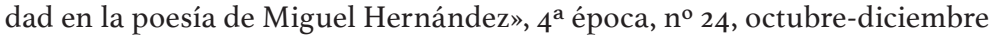
I952, pp. 57I-595). Los censores del franquismo, aún en una altísima institución como la Biblioteca Nacional, habían arrancado bárbaramente las hojas 
correspondientes al artículo buscado (¡sobre tema tan peligroso!) antes de encuadernar cuidadosamente el volumen. Cualquier lector curioso puede verificar, aún hoy, este dato increíble (2009: I6).

\section{Según relata Francisco Martínez Marín, en I952:}

Jesús Hernández Mateo organiza en 1952 la Fiesta de la Poesía (2I de marzo), en Orihuela, que reviste gran esplendor, con la presencia de Carmen Conde y otros poetas de las provincias de Murcia y Alicante, recitando en la Cruz de los Caídos de la Catedral, poemas de Miguel Hernández y del propio Jesús Hernández, así como otros en la voz de Olga Calleja, locutora de Radio Murcia (SER), que instala líneas microfónicas y retransmite luego un resumen; hay visitas a la Biblioteca Pública y a la capilla de la Virgen de Monserrate, donde Carmen Conde entrega un ramo de flores (I973: II3)².

Cano Ballesta también traería a colación, en otro trabajo suyo posterior, las dificultades en consultar la prensa republicana publicada durante la guerra, mientras preparaba la edición de Poesía y prosas de guerra y otros textos olvidados, en edición del propio Juan Cano Ballesta y Robert Marrast (I977)³ , si bien Cano concluyó su parte en I970:

Encontré estos artículos por mi parte, y Marrast hizo algo parecido, buscando en revistas del frente rojo. Para ello tuve que ir al Ayuntamiento a pedir un permiso especial a su secretario, quien me dio una hojita que decía: «Se autoriza al señor Juan Cano a ver revistas del período rojo». Estas revistas, periódicos, panfletos y hojas del frente fueron cuidadosamente guardadas por el régimen franquista durante los años cuarenta y se conservan perfectamente encuadernadas en unos cincuenta volúmenes en la Hemeroteca Municipal de Madrid. [...] Porque se consideraron necesarias y fueron utilizadas después de la guerra civil como pruebas contra los intelectuales de la República en procesos judiciales y en las depuraciones de sospechosos (2012: 175).

Manuel L. Abellán fue el primer investigador que publicó, extractado, un expediente de censura de una obra de Miguel Hernández. Fue en su libro, ya citado, de I980 (I89-I9I). Se trata del expediente 4364-60, caja 2I/I29I4, relativo a la importación de 200 ejemplares de Antología, publicada en 1960 por la editorial bonaerense Losada.

José Antonio Miranda Encarnación y Juan F. Pérez Ortiz, con motivo del cincuentenario de la muerte del poeta oriolano celebrado en I992, recogen también en un artículo periodístico (I992: I-2) algunas observaciones

2 Mecanoscrito inédito presentado al Premio de Ensayo Ramón Sijé, convocado por el Ayuntamiento de Orihuela.

3 Edición de la que, por cierto, no consta documentación alguna en el AGA. 
del lector encargado de revisar la edición argentina de Antología, publicada en 1960 por Losada, y de la que Joaquín de Oteyza pretendía importar la cantidad de 200 ejemplares. En el mismo trabajo, los autores se refieren a las representaciones de la obra teatral El labrador de más aire en 196I, I968, 1971, 1972, 1974 y 1978, con la publicación de algunos breves comentarios de los lectores de turno. Otra obra teatral, Los hijos de la piedra, con solicitudes de representaciones en marzo de 1967 (Madrid) y octubre de ese mismo año (Valladolid), también es objeto de la atención de los mencionados autores de este artículo de investigación ${ }^{4}$.

Jesucristo Riquelme (2004: I72-I74), en el II Congreso Internacional dedicado a la figura del poeta oriolano, celebrado en octubre de 2003, rastreó las diversas puestas en escena de obras teatrales, tanto en España como en Francia o América Latina, con especial incidencia en los expedientes de censura conservados en el AGA.

Por su parte, José Carlos Rovira, ya en 2010, año en que se conmemoraba el centenario del nacimiento de Hernández, publicó otro artículo en el que reproduce, tanto algunos textos como imágenes de los mismos. Por ejemplo, se refiere al expediente relativo a la edición de El rayo que no cesa y otros poemas, publicada en Buenos Aires por Espasa-Calpe Argentina, del que se reproducen las asombrosas consideraciones del lector pertinente; o sobre la referida edición de Antología, de la también argentina Losada. Algunos expedientes que atañen a representaciones de obras teatrales hernandianas igualmente figuran en el artículo de Rovira, como las de Quién te ha visto y quién te ve y sombra de lo que eras (1968) y Los hijos de la piedra (1967) (2010: 65-67).

En el mencionado año 2010 se publicó el catálogo de la exposición «Miguel Hernández. La sombra vencida, I9IO-20I0», con título homónimo y al cuidado del mencionado José Carlos Rovira. Pues bien, en el tomo I de ese catálogo (20IOb: 332-36I) se dedica un capítulo a «Homenajes y censura», y se reproducen, fotográficamente (340-349), notas informativas de diversas comandancias de la Guardia Civil, de 1967, 1975 y 1976, en donde se informa de diversos actos de homenaje al poeta oriolano. También se reproduce la solicitud de autorización de representación de Los hijos de la piedra por la compañía Bululú, así como el informe posterior del lector (350-352), la solicitud de importación (356) de Antología (Buenos Aires, Losada, 1960), el informe correspondiente del lector (357), la autorización con condiciones para la importación de no más de Ioo ejemplares (358), o el oficio presentado por la editorial Plaza \& Janés para la publicación de Poemas (1964), con la relación de supresiones efectuadas en las galeradas.

4 Agustín Torreblanca López (1995) se ha detenido en la censura de la representación de obras teatrales. 
Xelo Candel Vila ${ }^{5}$ ha rastreado, de manera sintética y precisa, los expedientes de censura de ediciones de libros poéticos y de teatro hernandianos, en el ya citado número monográfico de la veterana revista Ínsula (2020: 12-17).

\section{Algunas conclusiones}

De la revisión de los expedientes de censura conservados en el AGA podemos extraer algunos datos y conclusiones. En primer lugar, sin considerarlos unos materiales fundamentales para la recepción por parte de la censura de la obra hernandiana y en general de la figura del poeta oriolano, sí que resultan importantes porque Miguel Hernández era valorado por el régimen franquista como algo más que un simple poeta, y prueba de ello es la contumacia en la persecución seguida por los aparatos represores del Estado sobre cualquier actividad cultural que llevara el nombre de Miguel Hernández. Cierto es que tal represión no fue siempre sostenida con la misma intensidad en el tiempo. Se fue abriendo la mano a medida que los dirigentes políticos advirtieron que no era posible poner puertas al mar, y por mera supervivencia del régimen, que evolucionaba hacia una mayor permisividad, siempre con limitaciones.

En el caso de las ediciones de la obra hernandiana, las mismas abarcan las décadas de los años 50, 60 y 70.

Cada edición de libro hernandiano lleva su oportuna tramitación administrativa; hacemos constar, en su caso, la existencia de otras reimpresiones o reediciones y las examinamos; se describe cada edición, tanto en su estructura externa como la introducción o prólogo, los criterios de edición y una valoración de la selección de poemas; y destacamos, cuando ha sido posible, algunas reseñas aparecidas tras la publicación de la edición concreta que nos ayudan a calibrar las aportaciones o novedades de la misma. También hemos considerado importante ofrecer un panorama del régimen jurídico de cada apartado, tanto para libros, obras teatrales y actos públicos, como censura radiofónica y gramofónica, y cinematográfica.

En los años 50 solo hay constancia documental de cuatro ediciones: $E l$ rayo que no cesa y otros poemas (Espasa-Calpe Argentina, 1949), Poemas (Seis poemas inéditos y nueve más, Col. Ifach, 195I) y Dentro-de luz y otras prosas (Arión, 1957). También se conserva el expediente de Obra escogida. Poesía. Teatro $^{6}$, que sufrió los ataques de algunos ultramontanos del régimen. En

5 «Los expedientes de la censura franquista sobre la obra de Miguel Hernández».

$62^{\mathrm{a}}$ ed.: Buenos Aires, 1957; $3^{\mathrm{a}}$ ed.: México, 1962. Agotada la edición (I.500 o 2.00o ejemplares al precio de 90 pesetas), fue prohibida la reimpresión y la venta de las reimpresiones editadas en Buenos Aires y México. Gracias a Da Lorena Cabello Ibáñez, técnica de Archivos del AGA, hemos podido localizar el expediente asociado a esta importante edición y otros expedientes de significativas monografías sobre el poeta oriolano. 
esos años, la censura se aplicaba con inflexibilidad, digna de mejor causa y, como sucede en otros órdenes de la vida, las amistades podían sortear los recovecos de la censura, como ocurrió con la edición de Poemas, al cuidado de Vicente Ramos y Manuel Molina, que en 195I salió a la calle con el título de Seis poemas inéditos y nueve más.

Con los años 60 el interés de los más jóvenes por la obra de Miguel Hernández se acrecienta, al mismo tiempo que su figura también se transforma en un símbolo de resistencia frente al régimen. $\mathrm{Y}$ las casas editoras respondieron a ese interés creciente con la publicación de ocho ediciones: Antología (Losada, 1960), 22 poemas. Homenaje de Estampa Popular a Miguel Hernández (nonata, Garrido, 196I), Poemas (Plaza \& Janés, 1964, y la 2a edición, de 1967), la 4 a edición de El rayo que no cesa y otros poemas (Espasa-Calpe Argentina, 1966), Poesías (Taurus, 1967, y 2ª edición, de 1968) y Poemas de amor (Alfaguara, 1969).

En los años 70, la sociedad española ha evolucionado, y con ella los criterios de los censores. Si bien en los dos primeros años de la década (1970 y 197I) se vivieron momentos de retroceso por las contradicciones internas del propio régimen, las ediciones de bolsillo y las reediciones cubrieron un importante hueco en la formación literaria (y política) de aquellos jóvenes, que no entraban en contradicción con las numerosas versiones musicadas de poemas hernandianos. En el AGA se conservan los expedientes de las principales ediciones hernandianas publicadas en esta década, salvo las siguientes: Antología poética (Agrupación Nacional del Comercio del Libro, 1976) ${ }^{7}$; Poesía y prosa de guerra y otros textos olvidados (Ayuso, 1977 ${ }^{8}$ ), y Miguel Hernández para niños (Ediciones de la Torre, $1979^{9}$ ).

7 Introducción y selección de Manuel Rodríguez Maciá, Madrid, Agrupación Nacional del Comercio del Libro, 1976. La introducción (pp. I-XVI) no destaca por nada especial, salvo la noticia del ingreso en el Partido Comunista por parte de Miguel Hernández y la fidelidad a su origen. Incluye algunos de sus primeros poemas. En ese mismo año 1976, se publicó Antología Popular de Miguel Hernández. Homenatge dels Pobles d'Espanya a Miguel Hernández, en Butlleti del Collegi Oficial de Doctors i Llicenciats en Filosofía i Ciències del D. U. de Catalunya i Balears, julio de 1976, «Número Extraordinari dedicat a Miguel Hernández». Tampoco hay constancia documental del mismo. Su contenido es el siguiente: «Homenaje de los Pueblos de España a Miguel Hernández», p. 7; «Presentación», pp. 9-I3; «Esbozo biográfico», pp. 15-I7; «Antología», pp. 23-91, e «Índice», pp. 93-94.

8 Recogidos por Juan Cano Ballesta y Robert Marrast, Madrid, Ayuso, 1977. En la «Presentación e intento de valoración» de Cano, comenta los poemas de juventud, la prosa poética, las biografías de toreros atribuidas a Hernández, la crítica literaria, la poesía revolucionaria y de guerra, y la propaganda y artículos publicados en periódicos del frente, contextualizando los textos de Miguel Hernández. En el apéndice, Marrast da a conocer la protesta en favor de Hernández publicada inicialmente en El Socialista (no en El Sol, como se creía) del i6 de enero de 1936 con motivo de una injusta detención por parte de unos guardias civiles. La bibliografía recoge las fichas de las obras sueltas publicadas durante la guerra.

9 Edición preparada y prologada por Francisco Esteve, Madrid, Ediciones de la Torre, 1979 (noviembre); $2^{\text {a }}$ ed. corregida y aumentada (septiembre 1980 ). 
Hemos localizado 47 expedientes de las ediciones publicadas en estos años 70: cinco reediciones de El rayo que no cesa y otros poemas (Espasa-Calpe

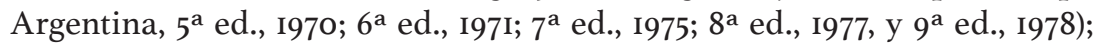
diez reediciones de Poemas (Plaza \& Janés, 1973; 1974; 1975 - dos ediciones en ese año-; $7^{\mathrm{a}}$ ed., I975; 1976 - un total de tres ediciones-; IO ${ }^{\mathrm{a}}$ ed., I977, y II ${ }^{\mathrm{a}}$ ed., 1978); siete reediciones de Poesías (Taurus, $3^{\mathrm{a}}$ ed., I970; $4^{\mathrm{a}}$ ed., I970; $6^{\mathrm{a}}$ ed., I973; $7^{\mathrm{a}}$ ed., I975; $8^{\mathrm{a}}$ ed., I976; $9^{\mathrm{a}}$ ed., I977, y IO ${ }^{\mathrm{a}}$ ed., 1979); cinco ediciones de Poemas de amor (Alianza Editorial, I $^{\mathrm{a}}$ ed., 1974; $2^{\mathrm{a}}$ ed., I975; $3^{\mathrm{a}} \mathrm{ed}$., $1976 ; 4^{\mathrm{a}} \mathrm{ed}$., 1978, y $5^{\mathrm{a}}$ ed., 1979); dos ediciones de El hombre y su poesía (edición frustrada en Anaya en 1970, y en Cátedra: I I ed., 1974); dos ediciones de Antología (Zero, $\mathrm{I}^{\mathrm{a}}$ ed., I974, y $2^{\mathrm{a}}$ ed., 1974), una edición de Perito en lunas. El rayo que no cesa (Alhambra, 1976); dos ediciones de Poesía (Narcea, $\mathrm{I}^{\mathrm{a}}$ ed., 1973, y $2^{\mathrm{a}}$ ed., 1976); cuatro ediciones de Obra Poética Completa (Zero-Zyx, I $^{\mathrm{a}}$ ed., 1976; $2^{\mathrm{a}}$ ed., 1977; $3^{\mathrm{a}}$ ed., 1978, y Colección Especial, 1979); una edición de Viento del pueblo (Lumen, 1977); tres ediciones de Poemas sociales, de guerra y de muerte (Alianza

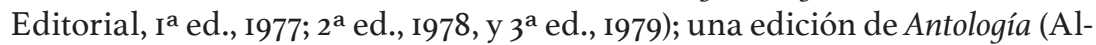
berto Corazón, 1977); una edición de Antología poética (Círculo de Lectores, 1978), una edición de Cancionero y romancero de ausencias (Lumen, 1978); una edición de El hombre acecha. Cancionero y romancero de ausencias (CUPSA, 1978); y una edición de Poesías Completas (Aguilar, 1979).

Durante los años 50 hemos contabilizado tres ediciones; en los años 6o, ocho ediciones, y en los años 70, cuarenta y siete ediciones, que suman cincuenta y ocho ediciones y reediciones o reimpresiones, más una de poesía de 1980 ( $9^{\text {a }}$ edición de Poemas, Plaza \& Janés). En total, cincuenta y nueve ediciones o reediciones. Las numerosas ediciones y reediciones aparecidas durante esta década ofrecen un variado abanico de intenciones y criterios, aparte de los intentos de recuperar zonas de producción poco difundidas por los preparadores de dichas ediciones porque habían sido vedadas por los censores de turno, como los poemas escritos durante la Guerra Civil o en la cárcel. De todos modos, se impone una visión generalista y abarcadora de todas las etapas creativas de la poesía hernandiana. En nuestra opinión, y sin restar méritos a las demás, las ediciones de Leopoldo de Luis y de Juan Cano Ballesta son las más equilibradas en cuanto a la selección y las que se han acercado a la obra de Miguel Hernández con mayor éxito pedagógico. De hecho, han sido recomendadas durante años a estudiantes de últimos cursos de Bachillerato. Las dos ediciones de Agustín Sánchez Vidal (I976 y 1979), la Obra Poética Completa de 1976 y la conjunta de Leopoldo de Luis y Jorge Urrutia (1978), fueron dirigidas a especialistas.

En cuanto a ediciones de obras teatrales hernandianas, publicadas en los años 60 son dos: El labrador de más aire (EDICUSA, ${ }^{\mathrm{a}}$ ed., 1968, y $2^{\mathrm{a}} \mathrm{ed}$., 1969); y, en los años 70, aparte de la $3^{\text {a }}$ edición de la obra anterior, El labrador 
de más aire, en $1973^{10}$, y la $4^{\mathrm{a}}$ edición en 1976, dos ediciones más: Teatro Selecto (Escelicer, I971; no llegó a editarse), y Teatro Completo (Ayuso, 1978). En total, seis ediciones entre los años 60 y los 70 . El teatro escrito por el poeta oriolano era un género poco atractivo para las editoriales y, por ello, es una parcela de su producción también escasamente conocida por parte del gran público en aquellas décadas.

Las representaciones teatrales de obras hernandianas no son numerosas debido, por un lado, a las dificultades técnicas de representación, y, por otro, a las cortapisas impuestas por las autoridades competentes del régimen, que dificultaron la promoción de puestas en escena. Son un total de diez representaciones, en diversas localidades, la mayoría de Madrid: una de Quién te ha visto y quién te ve (autorizada, Madrid, I968); seis de El labrador de más aire (prohibida, Madrid, I96I; autorizada, Madrid, 1968; no autorizada, Gandía, I971; autorizada, Madrid, 1972; autorizada, Madrid, 1973, y Sierra de Fuentes, en Cáceres, autorizada, 1978); tres de Los hijos de la piedra (no llegó a autorizarse ni a prohibirse porque los promotores dejaron en suspenso la representación, Madrid, I967, prohibida, Madrid, I967, y Madrid, 1970, prohibida). La tercera obra, Los hijos de la piedra, por su componente reivindicativo y político, fue prohibida en las tres ocasiones en que fue solicitada la pertinente autorización de representación.

Las obras teatrales o recitales basados en poemas hernandianos del periodo I97I-I978 comprenden ocho producciones: Canto de amor y sementera, Madrid, 197I, prohibido; Sino, nacimiento y muerte, Sevilla, 1972, autorizado; Pueblo de España ponte a cantar, 1975, se desconoce el resultado de la solicitud; Escenificación de poemas de Miguel Hernández, Bollullos Par del Condado, en Huelva, 1975, tampoco se sabe el resultado de la solicitud; Las cárceles, Sagunto, 1976, autorizada; Pastor de versos, Las Palmas de Gran Canaria, 1976, autorizada; recital de Jesús Enguita, desconocido, 1978, tampoco se conoce el resultado de la solicitud, y Fiesta de la Joven Guardia Roja, Madrid, I978, autorizado.

Miguel Hernández es uno de los poetas con mayor número de textos prohibidos en radio. Entre el Io de enero de 1964 y el 5 de junio de 1975 se deniega la difusión de la letra de nueve de sus poemas, algunos de ellos aparecidos en más de una «Relación de no radiables» y en diferentes años ${ }^{\mathrm{II}}$. La paradoja o sinsentido es que los textos no radiables habían sido previamente autorizados para su grabación.

En resumen, de los textos no radiables de Miguel Hernández, del periodo 1963-1976, hay veinte referencias, que a menudo se repiten. Del año

Io En el momento de finalización de este trabajo (enero 202I) hemos localizado la $3^{\mathrm{a}}$ edición, de 1973 (expte. 4542/73).

II Consultado en https://devuelvemelavoz.ua.es/es/censura/escritores-censurados-en-la-radio-franquista.html\#miguel-hernandez [12.5.2020]. 
I963, los sonetos del disco de Francisco Rabal; del año I964, dos referencias («Elegía», autorizado posteriormente el I7 de mayo de I967, y «Me tiraste un limón»); una de I966 («El último y el primero»); ocho de I97I («Sentado sobre los muertos», «El niño yuntero», «Vientos del pueblo me llevan», "Canción del esposo soldado», «Aceituneros», «No soy de un pueblo de bueyes», «Para la libertad» y «Fuego bajo tu piel»); tres de 1972 («Sentado sobre los muertos», «El niño yuntero» y «Para la libertad»); tres de I975 («Sentado sobre los muertos», "Vientos del pueblo me llevan» y "Canción primera»), y dos de I976 («Canción del esposo soldado»y «Juramento de la alegría»).

Los poemas prohibidos con más presencia en las listas de no radiables son: «Sentados [sic] sobre los muertos» (I97I, I972 y I975); «El niño yuntero» (I97I y I972); «Vientos del pueblo me llevan» (I97I y I975); «Canción de esposo soldado» (I97I, autorizado en I974; y I976); "Para la libertad» (I97I y I972). Después: «Aceituneros» (I97I), «No soy de un pueblo de bueyes» (I97I), «Juramento de la alegría» (I976), «Canción primera» (I975), «Elegía» (I964, autorizado en I967), «Fuego bajo tu piel» (I97I), «El último y el primero» (I966), «Me tiraste un limón» (I964), y «Sonetos» (I964).

Resultan llamativos los datos relativos al año I97I, con ocho textos considerados «no radiables», y al año siguiente, I972, con tres. Este fue el año en que se publicó el disco de Serrat dedicado a Miguel Hernández. Casi todos pertenecen al poemario escrito durante la guerra, Viento del pueblo.

En cuanto a las solicitudes de autorización de textos y grabaciones fonográficas, el resumen es el que sigue:

- I967: I (Discos Tempo).

- I968: II (Sonoplay: I; Zafiro: I; EDUMSA: 2; Fidias: 4; Discorama: 3).

- I969:3 (Fidias: I; Discorama: I; Penélope Discos: I).

- I970: 2 (Movieplay: I; Marfer: I).

- I97I: 2 (Edigsa: I; Hispavox: I).

- I972: 7 (Discos CBS: 2; Polydor: I; Publicaciones Controladas: I; Zafiro: I; Emi-Odeón: I; Productora de Grabaciones: I).

- I973: 4 (Discos Columbia: I; Cactus-Els 4 Vents: 2; Discos CBS: I).

Solicitudes denegadas:

- Año I970: I (algunas canciones denegadas de la solicitud de Marfer, S.A.).

- Año I97I: 2 (algunas canciones aceptadas y otras no de las dos solicitudes).

- Año 1972: I (se deniega la solicitud de Emi-Odeón para «Sentado sobre los muertos»).

- Solicitudes autorizadas:

- Año 1967: I.

- Año I968: II. 
- Año 1969: 3 .

- Año I970: 2 (algunas canciones aceptadas y otras no de una solicitud, de Marfer, S.A.).

- Año I97I: 2 (algunas canciones aceptadas y otras no de las dos solicitudes).

- Año I972: 6 (de la solicitud presentada por CBS, S.A., de fecha 8-IIII972, se deniega en primera instancia «Vientos del pueblo me llevan» y luego se rectifica tal decisión. Igualmente, de la solicitud de EmiOdeón, de fecha 8-IX-1972, de diez poemas se autorizan nueve y se deniega, como se ha adelantado, «Sentado sobre los muertos»).

- Año I973: 4 .

El año en que más solicitudes se presentaron (y aprobaron) fue I968. En I970 fueron presentadas dos solicitudes y de una de ellas, la presentada por Marfer, S.A., se autorizaron algunas canciones y se denegaron otras. En I97I se presentaron dos y de las mismas algunas canciones fueron autorizadas y otras fueron denegadas. Se trató de un año especialmente difícil. En 1972, de siete solicitudes presentadas, se deniega, como hemos adelantado, la de Emi-Odeón para «Sentado sobre los muertos».

También resulta interesante revisar otros datos estadísticos que ofrecen estas solicitudes, con un total de 7I poemas y I06 solicitudes. Por ejemplo, «Nanas de la cebolla» aparece en ocho ocasiones, como «Vientos del pueblo me llevan»; la «Elegía» dedicada a Ramón Sijé, en siete ocasiones. En seis ocasiones el poema «El niño yuntero». Otros poemas destacados por el número de solicitudes de grabaciones presentadas son: «Andaluces de Jaén» (el verdadero título del poema es «Aceituneros»), con cuatro solicitudes. Le sigue «Me llamo barro aunque Miguel me llame», con tres solicitudes; «Elegía a Federico García Lorca», también con tres; igualmente con tres solicitudes, «Sentado sobre los muertos», en las tres solicitudes, denegadas las grabaciones; también con tres, «Canción del esposo soldado» $\mathrm{y}$ «Tristes guerras».

Si bien las solicitudes conservadas datan de 1967, existen cinco discos publicados antes de los que no se conserva documentación en el AGA ${ }^{12}$ : Poe-

I2 Más adelante, tampoco hay constancia documental de los siguientes discos, que contienen versiones musicadas de poemas hernandianos: Nuestra Andalucía, de Jarcha; Este tiempo ha de acabar, de Elisa Serna, y Te recuerdo Amanda, de Víctor Jara, los tres de 1974. Seis en 1975: El cante de Paco Moyano; Vida e Morte de Amancio Prada; 4.444 veces, por ejemplo, de Adolfo Celdrán; A mis amigos, de Alberto Cortez, y Andalucía vive, de Jarcha; y a finales de ese 1975 o principios de 1976, Vientos del pueblo. No quiero ver el sol, de Jorge Cafrune. Cinco en 1976: Cadenas, de Jarcha; El color de tu mirada, de Mocedades; Está despuntando el alba, de Los Juglares (Sergio Aschero y Ángeles Ruibal); Cantata de Andalucía, de Luis Marín, y Las dos Españas, de Paca Quintero. Seis en 1977: Cantos de la resistencia española; De lunes a sábado, de Carmen, Jesús e Iñaki; Despegando, de Enrique Morente; Al compás del tiempo, de Laventa; No nos moverán, de Coro Popular Jabalón, y Llamo a la juventud, de Senda. Y siete en 1978: Joan Manuel Serrat canta a los poetas Antonio Machado, Miguel Hernández, Rafael Alberti, León Felipe; ... y regresarte (A Miguel Hernández), de Manolo Sanlúcar; Agua subterránea, de José Luis Zorro; Rocío de Lopera, 
sía de amor en castellano (1963); Francisco Rabal recita sonetos de Miguel Hernández y "Qué lástima» de León Felipe (1964); Antología poética (1966), en las voces de Francisco Rabal, Adolfo Marsillach, Carlos Lemos y Guillermo Marín. Rabal recitó los diez sonetos hernandianos; Poesías de Miguel Hernández (1966), y Francisco Rabal recita: Rafael Alberti, León Felipe, Miguel Hernández, Antonio Machado (1969).

En resumen, los treinta y dos discos editados de los que no existe documentación en el AGA, bien porque la misma desapareció por causas diversas (entre ellas, que no se presentara la pertinente solicitud) o porque la censura no se aplicó con el celo y rigor acostumbrados en los últimos años, son los siguientes: I963: I; I964: I; I966: 2; I969: I; I974: 3; 1975: 6; I976: 5; I977: 6, y $1978: 7$.

En relación con los actos públicos prohibidos relacionados con Miguel Hernández, nos ha interesado el homenaje tributado en la Universidad de Valencia en abril de 1967 y el llamado «Homenaje de los Pueblos de España a Miguel Hernández» en la provincia de Alicante en mayo de 1976, que supuso un intento de fomentar una cultura de base popular, claramente ideologizada.

En definitiva, nuestro proyecto, iniciado en 20II, pretende ofrecer una panorámica abarcadora de la censura desde diversas manifestaciones (ediciones de poesía y teatro, representaciones teatrales, obras o recitales de poemas hernandianos, radio y fonografía, actos públicos prohibidos) y, si bien no tenemos constancia de la existencia de películas o documentales sobre el poeta oriolano (un proyecto de película en 1978 no salió adelante), hemos considerado interesante concluir la investigación con un análisis del régimen jurídico que regulaba la censura cinematográfica.

\section{Bibliografía}

Abellán, Manuel L., «Análisis cuantitativo de la censura bajo el franquismo (1955-1976)», Sistema. Revista de Ciencias Sociales, 28, 1979, pp. 79-90.

-.Censura y creación literaria en España (1939-1976), Barcelona, Ediciones Península, 1980.

—. «Fenómeno censorio y represión literaria», Diálogos Hispánicos de Amsterdam, «Censura y literatura peninsulares», 5, 1987, pp. 5-26.

Cano Ballesta, Juan, La imagen de Miguel Hernández (Iluminando nuevas facetas), Madrid, Ediciones de la Torre, 2009.

—. «Reelaboración de la imagen de Miguel Hernández», en Miguel Hernández. La sombra vencida, I9I0-20Io, Madrid, Sociedad Estatal de Conmemoraciones Culturales (SECC), 20I0, Tomo I, pp. I39-I47.

de Rocío de Lopera; Una carta en primavera, de José Vicente Grau; Gracias a la vida, del grupo Tarancón, y Canción última, del grupo alicantino Mezcla. 
—. «Reconsiderando las prosas de guerra: poesía, biografía, historia», en Miguel Hernández. Cien años después. El hombre, el escritor, el mito, eds. M. J. Porro Herrera y B. Sánchez Dueñas, Córdoba, Diputación Provincial de Córdoba-Universidad de Córdoba, 2012, pp. 173-192.

De Isabel-Estrada, María Antonia, De lo vivo y cercano. Censura y representación del teatro de Rafael Alberti en España durante el franquismo, Madrid, Sociedad Estatal de Conmemoraciones Culturales, 2002.

Gozalbo Gimeno, Daniel, «Historia archivística de los expedientes de censura editorial (1942-2017)», Creneida. Anuario de Literaturas Hispánicas 5, 20I7, pp. 30-31, https://www.uco.es/ucopress/ojs/index.php/creneida/article/view/I0367/9597 [8.4.2020].

Guerrero Zamora, Juan, Noticia sobre Miguel Hernández, Madrid, Cuadernos de Política y Literatura, 195I.

—. Miguel Hernández, poeta (I9Io-I942), Madrid, Col. El Grifón de Plata, 1955.

—. «Mi libro sobre Miguel Hernández», $A B C$, I2-VI-I98o, pp. 13 y I5.

Iravedra Valea, Araceli (coord.), Ínsula, «Verbo clandestino». Poesía, censura y autocensura bajo el franquismo, 879, marzo, 2020.

Lechner, Johannes, El compromiso en la poesía española del siglo xx. Parte segunda: de 1939 a 1974, Leiden, Universitaire Pers Leiden, 1975.

Manresa, Josefina, Recuerdos de la viuda de Miguel Hernández, Madrid, Ediciones de la Torre, 1980 .

Martínez Marín, Francisco, Antología crítica bio-bibliográfica de escritores oriolanos: 1850-1972, Orihuela, Ayuntamiento de Orihuela, 1973.

Miranda Encarnación, José Antonio \& Juan F. Pérez Ortiz, «Miedo a la palabra», Información, Alicante, 23-IV-I992, pp. I-2.

Montejo Gurruchaga, Lucía, «Blas de Otero y la censura española desde 1949 hasta la transición política. Primera parte de Ángel fieramente humano en castellano», Revista de Literatura, I20, 60, I998, pp. 49I-5I6.

—. «La relación de Ángela Figuera con la censura española: los expedientes de su obra poética», en Actas del XIII Congreso de la Asociación Internacional de Hispanistas. Madrid, 6-II de julio de 1998. Historia y sociedad comparada y otros estudios, eds. F. Sevilla Arroyo y C. Alvar Ezquerra, Madrid, Castalia, 2000, vol. IV, pp. I69-I77.

- «Blas de Otero. La palabra siempre bajo vigilancia. Censura y autocensura», en Compromisos y palabras bajo el franquismo "Recordando a Blas de Otero (1979-2009)». Actas del Congreso Internacional celebrado en Granada del 27 al 29 de enero de 20IO, coords. A. Iravedra Valea y L. Sánchez Torre, Sevilla, Editorial Renacimiento, 2010, pp. 183-196.

Riquelme, Jesucristo, «Puestas en escena del teatro de Miguel Hernández», en Presente y futuro de Miguel Hernández. Actas II Congreso Internacional, Orihuela-Madrid, 26-3o Octubre 2003, eds. J. J. Sánchez Balaguer, F. Esteve 
Ramírez y coord. A. L. Larrabide, Orihuela, Fundación Cultural Miguel Hernández, 2004, pp. 172-I79.

Rovira, José Carlos, «Perseguido después de muerto», Información, Alicante, 30-X-2010, pp. 65-67.

-. Miguel Hernández: La sombra vencida, I9Io-20Io, Madrid, Sociedad Estatal de Conmemoraciones Culturales, 20Iob.

Torreblanca López, Agustín, «Fuentes documentales para la historia del control administrativo de la representación de obras teatrales (19391985)", SIGNO. Revista de Historia de la Cultura Escrita (Universidad de Alcalá de Henares) 2, 1995, pp. 77-98, https://ebuah.uah.es/dspace/bitstream/handle/IOoI7/7477/fuentes_torreblanca_SIGNO_I995.pdf?sequence $=\mathrm{I} \&$ is Allowed $=\mathrm{y}[8.4 \cdot 202 \mathrm{O}]$. 